\title{
Atenea
}

Revista publicada por la Universidad de Concepción COMISION DIRECTORA:

Enrique Molina, Samuel Zenteno A., Luis D. Cruz Ocampo, Salvador Gálvez y Abraham Valenzuela C. (Secretario). EDITOR Y AGENTE GENERAL: CARLOS JORGE NASCIMENTO AÑO I DICIEMBRE DE 1924

NúM. 9

J. S. Barnes

\section{Bases del Facismo}

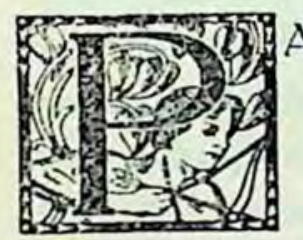

ARA darnos cuenta clara de la actual situación de Italia, es conveniente distinguir el facismo, partido politico. que tiene señalada una misión con fines inmediatos definidos, del facismo entendido como movimiento revolucionario y que representa un cierto orden de ideas.

El facismo. partido politico tuvo la suerte de encontrar, - en el momento psicológico, - un jefe de extraordinaria energía y actividad politica. Los facistas llegaron a restaurar en Italia la autoridad y eficiencia del gobierno y a contrarrestar las fuerzas anti-nacionalistas que obraban en el país, representadas por el socialismo. la democracia cristiana y la masonería. que se habian desarrollado libremente a la sombra de gobiernos anteriores. Estas fuerzas arrancan su inspiración de un ideal internacionalista. en oposición al nacionalismo o imperialismo. El socialismo. v. gr.. predica la solidaridad de los intereses de la clase proletaria, desentendiéndose del interés nacional, y se funda en una concepción materialista del universo.

La democracia cristiana reproduce. con un matiz de cristianismo. las concepciones ideológicas del radicalismo del siglo XIX, y considera a la religión. nó como una suprema autoridad nacional, que trata de armonizar los intereses nacionales con el verdadero derecho, sino como un lazo internacional que une a los cristianos de todos los países en una alianza que se sobrepone a sus obligaciones con sus patrias respectivas. A pesar de que el punto de partida de los demócratas cristianos es diverso, a pesar de que repudian la guerra de clases. su programa práctico difiere levemente del de los socialistas moderados. Por fin. la masonería es una organización internacional.

El común denominador de estos tres grupos es el internacionalismo. mientras 
que el facismo es esencialmente nacionalista. Es asi como, alrededor del facismo. se han congregado todas las fuerzas nacionales de Italia, sean liberales, conservadoras o católicas. El facismo ha descompaginado los antiguos sistemas de partidos en Italia. La mayoria de los sindicalistas, por ejemplo, o han estrechado sus filas. o se han convertido al facismo, abandonando su alianza con los socialistas; porque el sindicalismo no es incompatible con el nacionalismo y no excluye la idea de cooperación de clases. El partido popular católico se ha dividido, y. asi, tenemos. de una parte. los nacionales católicos, que solidarizan con el lacismo, y de otra, los restantes, que se adhieren a los principios de la democracia cristiana.

El facismo, considerado como movimiento revolucionario que representa un determinado orden de ideas, sobrepasa enteramente en importancia al facismo partido político. como al presente está constituido. Propiamente hablando. a este movimiento revolucionario no deberiamos llamarlo facismo. Ya apuntaba en la conciencia. allá por los años que precedieron inmediatamente a la guerra. Tiene su verdadera base en el movimiento del Renacimiento. y sólo fué relardado por los acontecimientos históricos y por ciertas tendencias prácticas dominantes. Pero, aho. ra. dentro del partido facista, las ideas revolucionarias han empezado a tomar expresión consciente; y porque esas ideas reflejan el alma misma de la tradición italiana, el partido facista pari passu con la consecución de sus fines primeros, se va identificando con ellas y encontrando en ambas su razón de ser y su base popular. Dentro de las filas del partido facista. esas ideas se están elaborando y aclarando. Pero no se puede decir que todos sus prosélitos actualmente las aceptan: hay muchos de los llamados facistas que se han incorporado al partido en la hora de su triunlo por razones de puro oportunismo. y aun hay quienes lo han hecho con propósitos deshonestos. Hay otros, por el contrario. que son genuinamente nacionalistas de sentimientos. pero que no tienen ninguna o muy poca participación en el movimiento.

Pero la verdadera contienda que se libra en Italia no obedece tanto a razones de nacionalismo contra internacionalismo como a la divergencia entre las ideas más antiguas que informan el movimiento facista y las que hasta ahora han inspipirado a Italia y a la mayor parte de Europa desde la Revolución Francesa. Si este movimiento triunfa en Italia, traspasará con mucho sus fronteras. Es de mucha actualidad e importancia. por lo tanto su acertada comprensión.

Mucha confusión de ideas ha producido en Italia como en otras partes la necesidad de distinguir entre el epartido facista, y el emovimiento revolucionario facislas. Este último lo llamaremos simplemente facismo, aunque más exactamente podriamos llamarlo eromanismo, como lo veremos más adelante. Muchos italianos creían que una vez que las fuerzas nacionalistas o las internacionalistas quedaran acentadas o dispersas, como lo han sido ya, a excepción de las fuerzas internacionales-. una vez que la autoridad y la eficiencia del gobierno quedaran establecidas, una vez que se hubieran efectuado en la Constitución los cambios destinados a eliminar cualquiera posibilidad quedara expuesto a caer de nuevo en los antiguos malos sislemas, el facismo se reduciria a un simple partido político. diferiendo de los demás partidos nacionalistas sólo en los puntos especificos de 
su programa. Pero esas personas han debido desilucionarse. Los dirigentes facistas, ahora más que nunca, insisten en que lo que han hecho. están y continuarán haciendo, es llevar a cabo una revolución.

¿Cuál es el signnificado exacto de esta afirmación? Esto significa que los facistas se proponen cimentar el Estado sobre cierto orden de ideas fundamentalmente diferente del que dominara hasta aqui. Significa que aquellos italianos que se mostraran disconformes con las ideas facistas serán considerados como rebeldes. tal como los anti-nacionalistas lo están siendo ya por la mayoria de los italianos. Significa que el carácter revolucionario del lacismo no cesará. no podrá cesar, hasta que fodo el país se pueda considerar convertido. y alejado todo peligro de reacción. hasta que la doctrina lacista haya encontrado plena expresión en la Constifución y hasta que la vida politica de la nación se desarrolle enteramente dentro de los moldes facistas. de tal modo que, aunque los partidos politicos futuros puedan diferir en sus distintos programas. estén. sin embargo. acordes en sus ideas lundamentales.

Podemos esclarecer este último punto con un ejemplo de la historia de Italia. La revolución que llevó a efecto la unidad italiana lué dirigida. como casi todas las revoluciones. por una minoría activa. y contó con el apoyo tácito de la gran masa.--podemos decir. consecuentemente. que interpretaba la voluntad popular, - contra la oposición activa de los contrarios a la idea de la unidad. Formaban entre eslos últimos: los católicos. o más bien dicho. clericales, alarmados por las consecuencias que la unidad de Italia tendría para la Iglesia Católica. que perdería con ella su poder temporal: los conservadores, temerosos de que la unidad italiana pudiera significar el triunfo de las ideas de la Revolución Francesa: y una multitud de gente cuyos intereses resultarian perjudicados con el cambio. Tan pronto como la revolución hubo triunfado. los opositores a la unidad, derrotados por la fuerza. se encontraron ante esta alternativa: o se sometian ante la evidencia de los hechos consumados. o quedaban al margen de la vida del Estado: porque. mientras ellos repudiaran los principios fundamentales sobre los que todo gobierno de Italia unida debia en adelante descansar. no tendrian ninguna participación en ningún gobierno de Italia.

De la misma manera, hoy. todos los partidos nacionalistas están de acuerdo en que aquellos italianos que permanecen adictos a una o a otra forma de internacionalismo politico se hallan tan al margen de la vida nacional como jamás lo estuvieron los que rechazaron la unidad italiana. Son tolerados tanto como es posible tolerarlos. Pero el facismo va más allá. No son solamente los internacionalistas los que están siendo presionados. sino todos los desafectos a ciertas ideas aparte del nacionalismo. Es ésa la batalla en que Mussolini figura como un gran leader revolucionario. Pero la jornada decisiva no se ha librado aún: asistimos todavía a los preliminares estratégicos de la maniobra. Las fuerzas de la oposición no han tomado sus posiciones definitivas. Los elementos nacionalistas. que no se allanan a aceptar todas las ideas del facismo. se encuentran frente a un difícil dilema; si ellos retiran su apoyo al partido facista, quedan a merced de sus enemigos por principio. los internacionalistas; de manera que se ven reducidos a 
permanecer a la espectativa de los acontecimientos. Niegan hechos de claridad meridiana. como que el facismo es, a todas luces, revolucionario. y se están engañando a si mismos, (fenómeno psicológico bien común frente a acontecimientos desagradables), con la idea de que el facismo ha terminado ya su obra y que la vida de Italia reasumirá dentro de poco su aspecto normal de antes de la guerra y antes del peligro bolchevique de post-guerra. Es curioso que esla misma actitud se refleje en la prensa extranjera, talvez por la misma razón. .El deseo es el padre del pensamiento, y en Europa, el triunfo de la reacción contra las ideas politicas dominantes, es desagradable para mucha gente, no tanto porque las ideas nuevas sean rolundamente inaceptables, sino porque, siendo nuevas y en contraposición con los actuales modos de pensar, son desconcertantes.

Las últimas elecciones en Italia han afirmado enormemente el poder de Mussolini. Los resultados fueron los de un verdadero plebiscito en su favor. Hasta entonces había tenido que luchar en cada momento por mantener la unidad de su partido frente al Parlamento, que estaba siempre listo para aprovecharse del menor indicio de división dentro de las fllas facistas. Por eso, mientras existía el Parlamento anterior. Mussolini concentraba su atención principalmente en mantener erguida la bandera nacionalista que levantara el facismo, en afirmar la autoridad y eficiencia del gobierno y en despachar una cantidad de reformas urgentemente reclamadas y referentes a todas las ramas de la Administración. Aquel Parlamento, en atención a la sólida base del gobierno en el país, y al hecho de estar la fuerza armada en manos de Mussolini, decidió acordar al Ejecutivo amplios poderes para llevar a cabo estas reformas. Fuera del deseo de Mussolini de no apelar al veredicto popular antes de haber demostrado prácticamente la eficiencia de su gobierno, no habia ya necesidad inmediata de nuevas elecciones. Pero. consumada la primera fase de la revolución. llegó la hora de avanzar un nuevo paso: el facismo necesifaba purificarse, eliminando a sus miembros indisciplinados. a aquéllos que se habían enrolado con falsas pretensiones o que fueran incapaces de comulgar con todas las ideas fundamentales del facismo. El primero de estos objetivos ya lo puede alcanzar Mussolini, porque es tan incontrastable su poder en el nuevo Parlamento, que puede permitirse castigar o alejar de su servicio a todo facista que no se someta a una extricta disciplina. El segundo lo podrá llevar a efecto gradualmente durante los cinco años venideros, porque la gran mayoría actual. que está compuesta de otros elementos además del partido facista, le da una oportunidad y una libertad excepcionales para educar y uniformar la opinión pública en el credo doctrinario que él desea ver triunfante en toda la Peninsula. Mussolini mira estos cinco años, no sólo como un período consagrado a una ardua labor de reformas, sino como una era de preparación y educación en que las doctrinas del facismo han de aclararse y definirse. Al cabo de ellos, estará en situación de llamar al pueblo a un nuevo veredicto y de dar por terminada la revolución. si es que se la puede llamar terminada al dejar asentadas las bases definitivas. Expondremos a continuación las ideas fundamentales sobre que se basa este movimiento.

-La Nación no es solamente la suma total de los individuos que en ella 
- viven: mucho menos podrá ser el instrumento de los partidos: es un organismo - que comprende la serie ilimitada de las generaciones, de que los individuos - no son más que elementos transitorios; es la sintesis suprema de los valores - espirituales y materiales de la raza. El Estado es la encarnación legal de la - Nación. Las instituciones políticas son eficientes en la medida en que los valores - nacionales encuentran en ellas expresión y protección. Estas declaraciones. hechas por Mussolini en la primera reunión de los diputados facistas elegidos en 1921, son demasiado abstractas para coustiluír por si solas la base de una doctrina del Estado, porque su aplicación depende de la interpretación que se dé a los valores nacionales. Esta es, sin embargo, una clave para la mentalidad facista, y no es raro que desde 1921 la teoria más concreta del Estado. la que está actualmente en evolución dentro de las filas facistas. se haya ido aproximando más y más a la concepción tradicional latina, interrumpida en su evolución por la nueva mentalidad surgida a raiz del Renacimiento.

La tradición latina gravita alrededor de un Estado universal y una Iglesia universal. El primer principio del facismo es que el Estado existe, nó por motivos tan leves como la protección de la sociedad contra la disgregación o para el mantenimiento de las leyes y el orden. ni para fines tan vagos como el bienestar general o la mayor felicidad del mayor número. sino que para servir y difundir un determinado acervo de ideas universalmente aplicables en todas las naciones y a todas las clases. La acusación que el partido popular hace al facismo de que pretende deificar al Estado. carece de fundamento. Al contrario, da al Estado un ideal universal. colocando sobre él una ley moral a la que tiene que servir en su calidad de organización temporal.

No es fácil definir ese ideal, pero puede explicarse como una resurrección. una readaptación a los ideales medioevales: mejor aún, se le puede identificar con el sRomanismo., que en la Edad Media ya se había fundido con el catolicismo. Un ejemplo ilustrará este concepto. El facismo concibe la soberania como mandato divino. En los tiempos que corren, esa soberanía debe ser ejercida por el Estado, es decir. por el Gobierno. siendo el más perfecto que se concibe una jerarquía de la autoridad con ancha base popular. sobre todo entre los fieles. tanto por razones morales como de conveniencia. Pero la autoridad, delegada por Dios. cesa automáticamente de serlo cuando y donde deja de servir su causa. Al pueblo le asiste, por consiguiente. un derecho teórico de rebeldia cuando el Gobierno cesa de cumplir su deber: y el Gobierno está en el derecho de ejercitar la coerción cuando y donde los individuos se muestren desafectos o incapaces de practicar el ideal moral, que es obligación del Estado mantener. Así. la libertad no es un derecho abstracto. sino un medio para concentrar alrededor del Estado todas las fuerzas vitales de la Nación. El grado de libertad susceptible de concederse depende, pues, de las circunstancias, las que variarán de acuerdo con la educación, el sentido de la responsabilidad de los ciudadanos y el grado de seguridad en que se encuentren el Estado y las ideas que sustenta. El voto no es un simbolo de la ciudadania libre. sino un mecanismo destinado a proporcionarse un gobierno de probada eficiencia. 
Según las palabras de Mussolini: Los sistemas representativos responden a una necesidad de mecanismo más que de moral.. El gobierno. que es un arte. deberia ser ejercido por una aristocracia. La democracia, en el sentido exacto de la palabra. es un sistema poco razonable de gobierno, aplicable sólo en condiciones muy señaladas. La palabra soberano, aplicada a la muchedumbre, es una burla sangrientas: y nadie puede decir dónde empieza lo que llamamos el pueblo. ni dónde termina.

Sin embargo, el Gobierno.- - siendo el Estado representante temporal de Dios. - debe tener en la sociedad, en conjunto, su mayor preocupación. La aristocracia no debe constituírse por la atención exclusiva de sus intereses. como un Estado dentro del Estado. Sus deberes, tanto como sus derechos, son universales. De ahi que la República. en relación con la dinastia, sea la forma ideal de gobierno. Sus relaciones con los demás Estados se rigen también por la ley moral. Esta es la verdadera tradición latina o romana. Si no se ha observado en todas sus partes, es por razones accidentales de conveniencia.

En el gobierno de la Iglesia Católica está puesto en práctica este sistema ideal de gobierno. Es una sociedad perfecta. Todos y cada uno de los oficios se hallan expeditos para todos los que demuestren estar en posesión de las condiciones requeridas: y asi, dentro de la Iglesia Católica, se ofrece la oportunidad de llegar a ser autoridad a todos los individuos, sin distingos de clases ni de origen. Los diferentes oficios exigen diferentes condiciones, ya sea habilidad, ya conocimiento o experiencia en alguna materia determinada, santidad, modales refinados, un conocimiento práctico del mundo, etc.: pero ninguna condición particular constituye un pasaporte para todos los oficios. Esta organización es una jerarquia. Culmina en una autoridad suprema, pero está basada enteramente en la masa de los fieles; se puede comparar con una pirámide. comparación lavorita de Mussolini. Pero, más que a una pirámide. se asemeja a una gran catedral que culmina en la cúpula. tan sólidamente basada como la pirámide, pero mucho más diversificada en rasgos menores de arquitectura, cúpulas secundarias, pináculos o torres que representan, en el Gobierno de la Iglesia, sus muchas y variadas organizaciones autónomas, v. gr.. las grandes órdenes religiosas.

Las instituciones representativas, que fueron inventadas por los monasterios de la Edad Media, son utilizadas cuando y donde pueden rendir buenos resultados. La democracia se limita. donde llega a usarse, a los asuntos de la parroquia. La Vox Populi, que a menudo es en la práctica Vox Dei. tiene el derecho de ser oida. La autoridad tiene el deber de mantenerse en contacto con la opinión y de procurarse los medios que le permitan oirla. El Papa concede diariamente audiencias y recibe peticiones de personas de toda condición, informes de todos los lugares y está tan al corriente de los acontecimientos como el que más.

Es parte del credo lacista que la Vox Populi debe más bien estar reflejada en un solo individuo, a salvo de las luchas partidaristas, que no en una asamblea que representa solamente la suma de las tendencias divergentes y donde las 
ambiciones personales juegan un papel tan apreciable en la formación de la opinión.

La revolución facista, consecuentemente, no quedará terminada hasta que los principios que informan el gobierno de la Iglesia Católica hayan encontrado expresión concreta en las instituciones del Estado de Italia y. por su intermedio. se haya creado una nueva clase gobernante. Cualquiera tentativa de reacción antes que estos fines hayan sido firmemente cimentados, será, si es necesario. sometida por la fuerza, pero donde los métodos constiiucionales basten, de ellos se hará uso. Mussolini no es un doctrinario: no cree en la improvisación de una Constitución nueva. El cree más bien que se debe construir sobre los viejos cimientos, adaptando las antiguas instituciones a las ideas nuevas.

Si tales reformas constitucionales son necesarias, se llegará a ellas, modificando los planos originales en el sentido que nos aconseje la experiencia. Tal es su propósito. De acuerdo con él. no se puede predecir con exactitud lo que será la Constitución dentro de cinco años o diez años.

Mussolini no se propone disolver la Cámara de Diputados. Esa Asamblea. dice, tiene importantes funciones que Ilenar, aunque en la experiencia parezca que su utilidad real ha cesado. Es un órgano de la opinión pública; es una escala del talento político: es un medio para que la critica pueda aplicarse a los proyectos de legislación: es un medio de defensa contra los abusos de poder de las autoridades; y así, viene a ser propiamente una garantia de la Constitución. Se le puede encomendar la función de fiscalizador en el gobierno del Estado: pero no tiene el derecho de reclamar para sí toda la soberania. ni menos lo tiene de paralizar el gobierno responsable establecido. La ley Acerbo fué el primer paso encaminado a hacer de la Cámara de Dipulados un cuerpo más serio. Permite que el partido que cuente con mayor número de votos en todo el país (siempre que obtenga como mínimum el $25 \%$ del total de votos emitidos) tenga los dos tercios de la representación. Esta medida es garantia de gobierno estable durante un periodo de legislatura que asciende a cinco años. Así se destierra la rolación de los partidos que caracterizó a las Cámaras anteriores-donde era materialmente imposible para cualquier partido formar una mayoria efectiva.- y se da una base a la crítica seria. Por lo demás, todos los otros partidos están representados proporcionalmente en el tercio restante de la Cámara. Hay un comité encargado de hacer observar las reglas en el debate; esto, sin duda. provocará un nuevo avance. Después, es posible que se reduzca el número de diputados en las próximas elecciones y podremos esperar que se establezca la práctica de que los debates de toda la Cámara que terminen con un voto de confianza, sólo lengar lugar al tratarse de la politica general de un ministro o en casos de excepcional importancia.

Una innovación más importante todavía en la Constitución. que se espera de este periodo legislativo, se refiere al movimiento de la Unión Comercial Nacional Facista. Este movimiento, que ya cuenta arriba de dos y medio millones de adherentes, rehusa la lucha de clases y reune a los obreros y empresarios en corporaciones destinadas a cooperar en beneficio de la empresa. Los dirigen- 
tes de estas instituciones están a punto de constituirse en legisladores en las materias de su incumbencia, y es probable que sus representantes se incorporen al Senado. que más que nunca quedaría convertido en la casa de los expertos. Aun más, las prerrogativas que al Rey confiere la Constitución es probable que sean duplicadas y con ello, su posición dentro de la Constitución se revestirá la mayor importancia. De tal modo que cualesquiera que sean los cambios que veamos en el período que se inicia, la balanza de los poderes será modificada. Posteriores medidas de transformación se adaptarán, nó las del sistema federal que propician las regiones, que es desechado por el facismo como elemento de desunión, sino en el sentido de garantir. lo más ampliamente posible, la autonomía local a las grandes ciudades históricas y a los municipios (municipia) que son asiento de las arquidiócesis: lo que está de acuerdo con el sistema romano de gobierno y en perfecta armonía con las tradiciones regionales mantenidas a través de los siglos

De nada sirve, sin embargo, especular acerca de las posibles medidas que adaptará el facismo para armonizar el país y la Constitución con los principios generales; es inútil, por ejemplo, divagar sobre la duración de la dinastía de Saboya. El facismo, como hemos visto, a pesar de los acontecimientos, sigue la huella de Roma. fundamentalmente republicana. Sin embargo. Mussolini, que, con un claro sentido de la actualidad, como verdadero estadista, en atención al tiempo y a las circunstancias, a menudo se desentiende de su lógica, ha aceptado la casa de Saboya como un elemento necesario al actual estado de cosas, contribuyendo a la estabilidad y unidad del país; y ha comprobado que Italia posee. en el Rey Victor Manuel, un monarca dotado de las cualidades intelectuales que se requieren para ejercer las funciones politicas que el facismo desea encomendar al jefe del Estado en el presente momento de transición. La suerte de la casa de Saboya está, pues, en sus propias manos.

Las relaciones de Italia con el Vaticano están destinadas también a sufrir transformaciones: pero sería ocioso tratar de inquirir cuándo y en qué sentido. Es sabido que Italia desea ver a la Iglesia libre en el ejercicio de sus actividades espirituales y querría disipar cualquier sospecha de que el Papa sea o pueda ser un prisionero dentro del Estado de Italia; sólo así puede el Papa ejercer el máximo de su influencia en el mundo. y sólo así puede Italia cooperar con el Papado sin dañar la causa a que debe ir unida. Mussolini ha declarado que, para ser buenos italianos, deben ser buenos católicos. En orden a conseguir este fin, él ha restaurado en las escuelas la enseñanza de la religión, ha aumentado los sueldos del clero y. prácticamente, lo ha dejado exento del servicio militar; ha restituido la religión a un lugar de honor en las funciones del Estado. En ésta y otras formas ha fortificado la posición del catolicismo en el país y ha confirmado el hecho de que la católica es la religión oficial del Estado. Medidas más extensas están en esfudio, que darán sus frutos muy a tiempo para las relaciones entre el Quirinal y el Vaticano.

Entre tanto. se puede pronosticar la imposibilidad de un divorcio entre el facismo y el catolicismo. Y esto, no tanto por la dificultad en que se encontraría 
un gobierno italiano que marchara en desacuerdo con la mayoría de los italianos. que son calólicos, como porque la antigua tradición latina no concibe a Dios como verdadero soberano de otra manera que en la forma amplia en que la Iglesia lo concibe. El catolicismo debe ser, pues, condición sine qua non del Estado Facista, a pesar de que, es interesante notar, ningún facista admitiria que la Iglesia se mezclara como autoridad independiente en el poder temporal por delegación divina del Estado.

Tomado en su conjunto, todo esto no viene a ser más que un revivir de la idea del Sagrado Imperio Romano como una teoría de Estado.

Hemos tratado de presentar la situación actual de Italia en una forma tal que el lector comprenda que es éste el movimiento de una fuerza dinámica que se abre camino, desenvolviéndose y adaptándose a las modernas condiciones: nó un fenómeno que se ha operado y va quedando estático. Pero tenemos ya la clave de la situación, y será difícil citar ejemplos como éste: no es mera coincidencia el hecho de que encontramos todas las doctrinas facistas del Estado ligadas a los tratados sociológicos de los teólogos católicos. Las teorías católicas de la propiedad privada, de la libertad, de la persecución, de la relación entre los deberes y los derechos de los individuos con los de la comunidad y del Estado en relación con otros Estados, son adoptadas en todas sus partes por el facismo. La lógica. la casuística, que es la ciencia de lo bueno y de lo malo aplicada a las acciones. el realismo tanto como el idealismo de Mussolini, son del mismo modo el reflejo de la mentalidad del escolástico Santo Tomás y del jesuíta Suárez, tanto como de Maquiavelo, que se educó en la vieja tradición y que fué favorablemente comentado por Mussolini en su tesis para optar al grado que había de conferirle la Universidad de Bolonia. Otro ejemplo tenemos en la actitud de Mussolini frente a la Liga de las Naciones, a la cual desaprueba,_en la forma como está actualmente organizada,- - porque su punto de mira parece ser más la paz que la justicia, y. sobre todo, más que la justicia católica.

En fin, el facismo se puede explicar como el resurgimiento del espiritu latino en contraposición con el espíritu de la Europa del Norte. de las ideas católicas en contraposición con las ideas de la Reforma y de la Revolución Francesa. de la mentalidad antigua contra la moderna, que es producto de la Reforma y del Renacimiento prematuros. La idea del Sagrado Imperio Romano surgió en una época en que la vieja Europa estaba en ruinas dentro de un Estado ya decrépito. El resurgimiento de esta idea se ha venido a operar hoy. que la Europa presenta otra vez todo el aspecto de un caos; pero esta vez, dentro de un Estado lleno de energía y cohesión. El rejuvenecimiento de Italia empezó con la conciencia de su vitalidad. La segunda etapa se debió a la conciencia de que, cualquiera que fuera la suerte que esperaba a Italia, la primera necesidad que se imponia era la unificación. El precio que hubo de pagarse por esta unidad fué un eclipse transitorio de la tradición pura, aunque se ven reflejos de ella en los escritos de Manzoni. Gioberti, Rosmini. Oriani y otros. Pero muchos italianos han seguido las huellas de la Revolución Francesa, el realismo anti-religioso, doctrinas ideológicas democráticas concepción abstracta de la libertad. Porque el Papado como poder temporal se 
interponia en el camino de la unidad italiana: porque el liberalismo y la democracia eran fuerzas que minaban la autoridad de los actuales gobernantes del pais, cuyos intereses se oponian a la unidad, es por lo que pudieron triunfar momentáneamente en Italia las ideas susodichas, en oposición a la tradición, que es popular más bien que demócrata y realista en su concepto de la libertad. Sin embargo, cuando el tiempo empezó a mitigar las esperanzas del conflicto con Roma, cuando se vió en la democracia y el liberalismo una fuerza desintegradora conducente a resultados opuestos a los que persiguiera en realidad la Revolución Francesa, como el de desterrar los privilegios de clases. la verdadera tradición italiana empezó de nuevo a tomar sus posiciones, e inmediatamente se apoderó de las conciencias cuando se hubo conseguido un justo desarrollo económico y la seguridad nacional se hizo efectiva por el hundimiento del Imperio de Austria.

Tal es el facismo. Reconoce que lo más intimo y prolundo en la vida de una nación descansa en la religión; y pretende hacer de la Iglesia una República de los Fiekos, un Sagrado Imperio, destinado a reunir en su seno, con el correr del tiempo, a todos los hombres. No hay nada de extravagante en la resurrección de esta idea, si se la considera, como se la mira en Italia misma, como un mero proyecto imperialista de una nación joven y naturalmente destinada a expandirse gradualmente.

Roma no se construyó en un dia: .Chi va piano, va sano; o chi va sano. va lontano. Un imperio es el resultado de infinita paciencia y constancia ejercida dentro de numerosas generaciones; a aquéllos cuya concepción del imperio no es sólo la de la fuerza, sino la de la propaganda de un ideal, pueden hacer uso de la paciencia. Además. si la idea que informa este proyecto de imperio. realmente corresponde a una necesidad humana universal, triunfará en un tiempo más o menos lejano, no tanto por la fuerza, como por convicción. Mussolini, con la gran afición de los italianos a dramatizar los hechos en todos sus aspectos, no se confunde fácilmente. Sin abandonar sus ideales, él sabe perfectamente cómo someterlos a la severa realidad de los acontecimientos del momento. Es así como. por ahora, las aspiraciones de expansión de Italia se circunscriben al campo de la economia. Sus pretensiones imperialistas deberán. por mucho tiempo aún, quedar reducidas a un ideal. Pero, entre tanto. ella podrá constiluirse en lugar de rendez-vous para todos los que comulguen con sus ideales y doctrinas de gobierno. $\mathrm{Si}$ estos ideales son justos o nó, no es cosa que vayamos a dilucidar en este articulo; respetemos el derecho que asiste a los lectores de formarse su opinión individual. Todo lo que hemos pretendido es contribuír a esclarecer el verdadero significado del facismo e insistir sobre la necesidad de observar su desarrollo. Bueno o malo, afortunado o desgraciado, constiluye una fuerza que hay que tomar en cuenta, porque detrás de ella está una nación fecunda y luerte, que es digna de llamar la atención del universo. 